\title{
Mixed convection of CuO-water nanofluid in a square enclosure with an intruded rectangular fin
}

Wendi Zhao, Aloke K. Mozumder, and Prodip K. Das

Citation: AIP Conference Proceedings 1980, 050004 (2018); doi: 10.1063/1.5044340

View online: https://doi.org/10.1063/1.5044340

View Table of Contents: http://aip.scitation.org/toc/apc/1980/1

Published by the American Institute of Physics 


\title{
Mixed Convection of CuO-Water Nanofluid in a Square Enclosure with an Intruded Rectangular Fin
}

\author{
Wendi Zhao ${ }^{1}$, Aloke K. Mozumder ${ }^{2}$, and Prodip K. Das ${ }^{1, \text { a) }}$ \\ ${ }^{1}$ School of Engineering, \\ Newcastle University, Newcastle upon Tyne, NE1 7RU, United Kingdom \\ ${ }^{2}$ Department of Mechanical Engineering, \\ Bangladesh University of Engineering and Technology, Dhaka, Bangladesh \\ a)Corresponding author: prodip.das@ncl.ac.uk
}

\begin{abstract}
Mixed convection of conventional heat-transfer fluids in enclosures has been studied extensively for many years due to their ever-increasing applications in many engineering fields. In comparison, less effort has been given to mixed convection of nanofluids in enclosures in spite of their applications in solar collectors, electronic cooling, lubrication technologies, food processing, and nuclear reactors. Mixed convection of nanofluids is a challenging issue due to the complex interactions among inertia, viscous, and buoyancy forces. Numerical methods are best suited to resolve some of these complex interactions. Here a two-dimensional numerical model has been developed for a square lid-driven enclosure with an intruded rectangular fin to understand the mixed convection of CuO-water nanofluids and to optimize fin geometry for maximizing the heat transfer. The numerical model has been developed using commercial finite volume software ANSYS-FLUENT for various fin geometries and validated with literature. The flow fields, temperature fields, and heat transfer rates are examined for different values of Rayleigh, Reynolds, and Richardson numbers for several fin geometries for maximizing the heat transfer from the fin to the surrounding $\mathrm{CuO}$-water nanofluid flow.
\end{abstract}

\section{INTRODUCTION}

The natural and forced convection of conventional heat-transfer fluids (such as air, water or oil) in enclosures (such as square, wavy, inclined, cylindrical annuli, or triangular) has long been a question of great interest in a wide range of fields [1-14]. Flow and heat transfer from such irregular surfaces are often encountered in engineering applications such that it is in great need to enhance heat transfer in the cooling system of microelectronic devices, flat-plate solar collectors, flat-plate condensers in the refrigerator, and underground cable system. However, conventional heat-transfer fluids used in heat-transfer applications have low thermal conductivity. Thus, there is a great need to develop new kind of fluids which are more effective in terms of heat transfer performances. Nanofluids are fluids containing metallic nanometer-sized particles suspended stably and uniformly in a base-fluid (such as water, ethylene glycol, etc.). The use of metallic nanoparticles in base-fluid results in higher thermal conductivities and heat transfer coefficients as compared to the base-fluid, making them more efficient for complex heat-transfer applications. Although many experimental studies have been conducted for various nanofluids showing their better thermal properties and thermal performances [15-17], it is not clear whether the enhancement of thermal conductivity would be beneficial for the mixed convection in the confined enclosures. Thus, there is a need to investigate mixed convection of nanofluids in enclosed spaces with or without fins. Since the space inside the enclosure is limited, the geometrical optimization of fins inside enclosures is tricky and often requires the constructal design approach. This approach is based on the constructal law, which was stated by Adrian Bejan as "For a finite-size system to persist in time (to live), it must evolve in such a way that it provides easier access to the imposed currents that flow through it" [18]. A reasonable number of experimental and numerical works has been 
performed for the geometrical optimization of fins for air or water filled cavities using the constructal design approach [19-24]. However, it has not been employed to the enclosures filled with nanofluids. Thus, we focus on the geometrical optimization of fins and enclosures filled with nanofluids by means of the constructal design concept. We have developed a two-dimensional steady-state numerical model to investigate the mixed convection flow of $\mathrm{CuO}$-water nanofluids in a square enclosure with an intruded rectangular fin and to optimize the fin geometry for maximizing the heat transfer. The constructal design method is used to obtain the optimum geometry, in other words, the one that has the maximum heat transfer between the nanofluid and the fin. The fin area and the aspect ratio of fin height and length are considered the degrees of freedom of the finite flux system. For these degrees of freedom, several values of the Rayleigh (Ra) and Reynolds (Re) numbers are considered.

\section{PROBLEM DESCRIPTION}

We consider a lid-driven square enclosure with a rectangular fin as depicted in Figure 1. This geometry includes symmetry boundary conditions on the left and right walls. Thus, it can be considered as a simplified geometry of an array of rectangular fins. Here, the top surface of the enclosure moves through the $x$-axis direction and a constant temperature $\left(T_{\min }\right)$ is defined on it. The fin surface is kept at a constant but higher temperature $\left(T_{\max }\right)$. In Figure $1, H$ and $L$ are the height and length of the enclosure, $H_{1}$ and $L_{1}$ are the height and length of the fin, and $A$ and $A_{f}$ are the areas of the enclosure and the fin, respectively. All exterior surfaces but the top surface are considered adiabatic and no-slip condition is applied. The dimensionless velocities $\left(u^{*}\right.$ and $\left.v^{*}\right)$ and temperature $(\theta)$ shown in Figure 1 are defined as

$$
u^{*}=\frac{u}{u_{\max }}, v^{*}=\frac{v}{u_{\max }}, \text { and } \theta=\frac{T-T_{\min }}{T_{\max }-T_{\min }}
$$

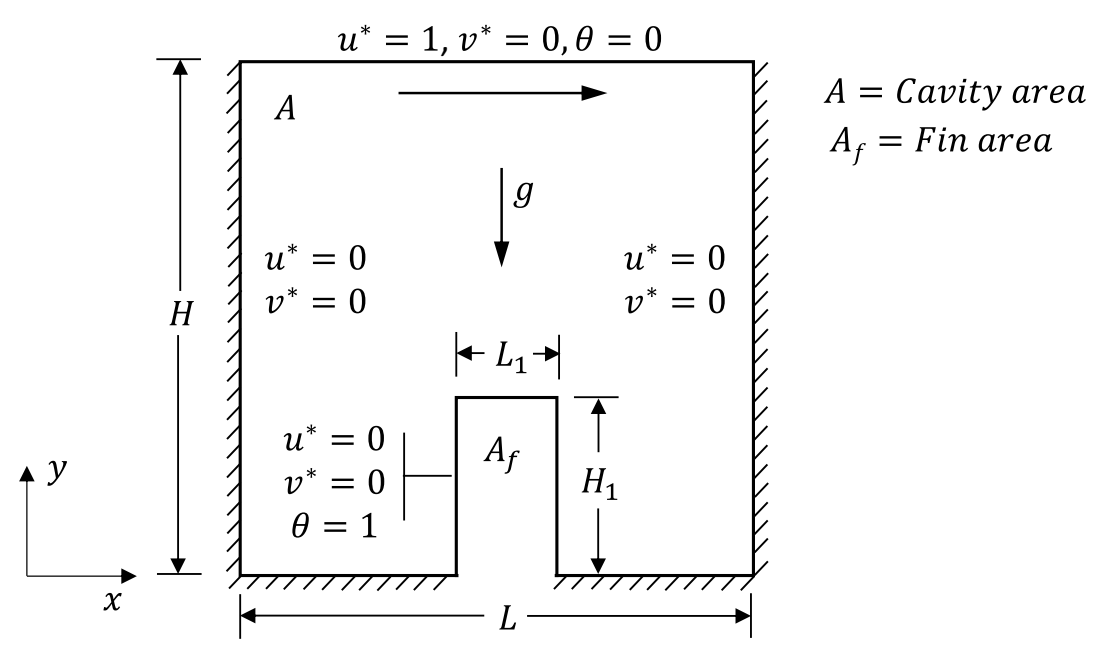

FIGURE 1. Schematic diagram of a lid-driven enclosure with a constant temperature rectangular fin at the bottom.

For the above enclosure, the governing conservation equations for the laminar, two-dimensional, steady-state mixed convection nanofluid flow and heat transfer with the Boussinesq approximation in the $y$-direction are written as [25]:

$$
\frac{\partial u}{\partial x}+\frac{\partial v}{\partial y}=0
$$




$$
\begin{gathered}
u \frac{\partial u}{\partial x}+v \frac{\partial u}{\partial y}=-\frac{1}{\rho_{n f}} \frac{\partial p}{\partial x}+\frac{\mu_{n f}}{\rho_{n f}}\left(\frac{\partial^{2} u}{\partial x^{2}}+\frac{\partial^{2} u}{\partial y^{2}}\right) \\
u \frac{\partial v}{\partial x}+v \frac{\partial v}{\partial y}=-\frac{1}{\rho_{n f}} \frac{\partial p}{\partial y}+\frac{\mu_{n f}}{\rho_{n f}}\left(\frac{\partial^{2} v}{\partial x^{2}}+\frac{\partial^{2} v}{\partial y^{2}}\right)+\frac{(\rho \beta)_{n f}}{\rho_{n f}} g\left(T-T_{\infty}\right) \\
u \frac{\partial T}{\partial x}+v \frac{\partial T}{\partial y}=\frac{k_{n f}}{\left(\rho C_{p}\right)_{n f}}\left(\frac{\partial^{2} T}{\partial x^{2}}+\frac{\partial^{2} T}{\partial y^{2}}\right)
\end{gathered}
$$

where $u, v, p$, and $T$ are the velocities, pressure, and temperature, respectively, and $\mu, \rho, \beta, k$, and $c_{p}$ are the dynamic viscosity, density, thermal expansion coefficient, thermal conductivity, and specific heat capacity, respectively. The subscript $n f$ represents the effective nanofluid properties. The effective nanofluid properties are estimated using the effective medium theory as it provides a reasonable estimate of effective properties and this theory has been widely accepted for multiphase systems [26-31]. The following expressions are used for the effective nanofluid properties:

$$
\begin{gathered}
\rho_{n f}=(1-\varphi) \rho_{f}+\varphi \rho_{s} \\
\mu_{n f}=\frac{\mu_{f}}{(1-\varphi)^{2.5}} \\
k_{n f}=k_{f} \frac{k_{s}+2 k_{f}-2 \varphi\left(k_{f}-k_{s}\right)}{k_{s}+2 k_{f}+\varphi\left(k_{f}-k_{s}\right)} \\
\left(\rho C_{p}\right)_{n f}=(1-\varphi)\left(\rho C_{p}\right)_{f}+\varphi\left(\rho C_{p}\right)_{s} \\
(\rho \beta)_{n f}=(1-\varphi)(\rho \beta)_{f}+\varphi(\rho \beta)_{s}
\end{gathered}
$$

where the subscripts $f$ and $s$ denote the base-fluid (water) and $\mathrm{CuO}$-nanoparticles, respectively. It is assumed that the shape and size of $\mathrm{CuO}$-nanoparticles are uniform and in thermal equilibrium with water. The radiative heat transfer and chemical reaction between water and $\mathrm{CuO}$-nanoparticles, and the viscous dissipation term in the heat transport equation are considered negligible. Thus, the thermophysical properties of $\mathrm{CuO}$-water nanofluid are assumed to be constant, except the density in the buoyancy term. The properties of water and $\mathrm{CuO}$-nanoparticles used in the numerical simulations are listed in Table 1.

TABLE 1. Thermophysical properties of water and $\mathrm{CuO}$-nanoparticles.

\begin{tabular}{ccc}
\hline Variables & Water & CuO Nanoparticles \\
\hline$C_{p}[\mathrm{~J} /(\mathrm{kg} \cdot \mathrm{K})]$ & 4179 & 540 \\
$\rho\left[\mathrm{kg} / \mathrm{m}^{3}\right]$ & 997.1 & 6500 \\
$k[\mathrm{~W} / \mathrm{m} \cdot \mathrm{K}]$ & 0.613 & 18 \\
$\beta[1 / \mathrm{K}]$ & $2.1 \times 10^{-4}$ & $8.5 \times 10^{-6}$ \\
$\mu[\mathrm{kg} / \mathrm{m}]$ & $1.002 \times 10^{-3}$ & - \\
\hline
\end{tabular}




\section{NUMERICAL MODELING}

The coupled set of governing nonlinear partial differential equations is solved numerically using the commercial finite volume based software, ANSYS-FLUENT. A second-order upwind scheme is used for the spatial discretization of the aforementioned equations. The velocity-pressure coupling is done by the SIMPLE algorithm and the pressure based solver is used to compute the solution. The solution of the governing equations is considered converged when the residuals are smaller than $10^{-6}$ for the mass and momentum equations and smaller than $10^{-8}$ for the energy equation. Once a converged solution is obtained, the average Nusselt number $\left(\mathrm{Nu}_{\text {avg }}\right)$ is calculated through the integration of the local Nusselt number $\left(\mathrm{Nu}_{H}\right)$ over the fin surface using the following expression

$$
\mathrm{Nu}_{\text {avg }}=\frac{1}{A} \int \mathrm{Nu}_{H} \cdot \mathrm{d} A
$$

Here area-weighted average value is taken as it divides the product of selected field variable and cell area by the surface area to give a dimensionless value.

A mesh independence test is performed through an extensive mesh test, which aims to guarantee a meshindependent solution and to find a suitable mesh size for the present analysis. The present meshes are tested by calculating the average Nusselt number between the fin and top wall. According to the current mesh test, the mesh size $100 \times 100$ ensures that the error is smaller than $1 \%$ and a $120 \times 120$ mesh provides results less than $0.5 \%$ of error. Thus, the $120 \times 120$ mesh is considered to perform the simulations as it seems reasonable for the current numerical problem. The data of the mesh test are listed in Table 2.

TABLE 2. Values of average Nusselt number for different mesh densities.

\begin{tabular}{ccc}
\hline Mesh Size & $\begin{array}{c}\text { Average Nusselt } \\
\text { Number }\end{array}$ & \% Error \\
\hline $80 \times 80$ & 22.169 & 2.103 \\
$100 \times 100$ & 22.301 & 0.627 \\
$120 \times 120$ & 22.411 & 0.490 \\
$160 \times 160$ & 22.480 & 0.310 \\
\hline
\end{tabular}

\section{RESULTS AND DISCUSSIONS}

The numerical results of mixed convection heat transfer and entropy generation for $\mathrm{CuO}$-water nanofluids in a lid-driven enclosure with a rectangular fin are presented in this section. First, the present numerical method is evaluated by means of a comparison with results available in the literature. Two cases are considered here. In the first case, a simulation of a convective flow in a partially heated rectangular enclosure filled with a pure fluid (water) is performed. The simplified geometry is considered with the omission of the intruded fin shown in Figure 1, which is identical to the geometry used by Oztop and Abu-Nada [32]. This geometry considers a heater on the left wall that is half the size of wall height and maintained at a constant temperature ( $\left.T_{\max }\right)$ higher than the right wall $\left(T_{\min }\right)$. The top and bottom walls of the enclosure are considered insulated. Details of this geometry and boundary conditions are available in Ref. [32]. A comparison between our numerical results and the results presented by Oztop and Abu-Nada for different Rayleigh numbers is provided in Table 3. As observed, the present numerical model provides a reasonable agreement with the data provided by Oztop and Abu-Nada [32]. In the second validation case, we used a geometry identical to Figure 1 but the enclosure is considered filled with $\mathrm{Al}_{2} \mathrm{O}_{3}$-water nanofluid. A case for $1 \% \mathrm{Al}_{2} \mathrm{O}_{3}$-water nanofluid is simulated for $\mathrm{Re}=1000$ and $\mathrm{Ra}=10^{5}$ and the numerical results of the present model are compared with the data available in the literature [25]. This comparison is shown in Figure 2. It is observed the comparison of predicted average Nusselt number $\left(\mathrm{Nu}_{\text {avg }}\right)$ shows a good agreement with the results reported by Cong et al. [25]. 
TABLE 3. Comparison of numerical results obtained using a partially heated square enclosure filled with water with those obtained by Oztop and Abu-Nada [32].

\begin{tabular}{cccc}
\hline & \multicolumn{2}{c}{ Nuavg } & Error \\
\cline { 2 - 3 } & $\begin{array}{c}\text { Oztop and Abu- } \\
\text { Nada[32] }\end{array}$ & Present Model & (\%) \\
\hline $\mathrm{Ra}=10^{3}$ & 1.020 & 0.990 & 2.941 \\
$\mathrm{Ra}=10^{4}$ & 2.011 & 1.952 & 2.934 \\
$\mathrm{Ra}=10^{5}$ & 3.981 & 3.873 & 2.712 \\
\hline
\end{tabular}

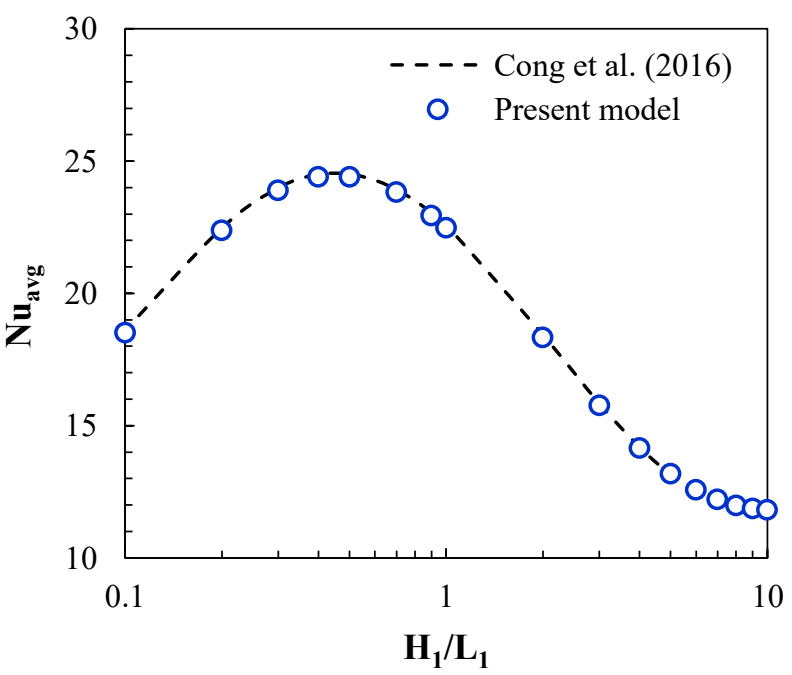

FIGURE 2. Average Nusselt number as a function of the fin aspect ratio $\left(H_{1} / L_{1}\right)$ and a comparison with published data for $1 \%$ $\mathrm{Al}_{2} \mathrm{O}_{3}$-water nanofluid in a lid-driven square enclosure with a rectangular fin [25].

The effects of different Reynolds (Re) and Rayleigh (Ra) numbers on the average Nusselt number $\left(\mathrm{Nu}_{\mathrm{avg}}\right)$ are compared. In this case, the fin aspect ratio $\left(H_{1} / L_{1}\right)$ is kept at 0.45 and the corresponding results are presented in Figure 3. For the effects of Rayleigh numbers (Figure 3a), it is noticed that with the increasing Reynolds number, though Rayleigh numbers are different, the four curves have an increasing trend. In addition, larger Rayleigh number leads to a higher heat transfer for low Reynolds numbers $(\operatorname{Re}<500)$. Although the increasing Reynolds number increases $\mathrm{Nu}_{\text {avg }}$, the effects of Rayleigh number are quite small for the entire range of Reynolds numbers (100 to 2000) for Ra $\leq 10^{5}$. Even increasing the Rayleigh number to $10^{6}$, the change is not obvious for a higher Reynolds number.

Figure $3 \mathrm{~b}$ shows the effects of Reynolds numbers on $\mathrm{Nu}_{\text {avg }}$ as a function of Richardson number. In this graph, four curves with different Reynolds numbers have the same increasing trend; however, the influence of Reynolds number is significant. The larger Reynolds number leads to stronger heat transfer and larger heat transfer increases. When the Richardson number is smaller than 0.1, convection inside the enclosure is predominantly forced convection. The change of $\mathrm{Nu}_{\text {avg }}$ is negligible in the range of $\mathrm{Ri}<0.1$, which is within the forced convection regime. As Ri number increases, the thermal transport becomes primarily the mixed convection, the heat transfer shifts rapidly. The heat transfer increases from fin side-surface as the buoyancy force increases with Rayleigh numbers due to the mixed convection. It means it is available to enhance the heat transfer through increasing the Rayleigh number. Corresponding isotherms for different Re numbers are shown in Fig. 4. One can easily observe that the temperature distribution is almost homogeneous over the fin top surface at low Re, while the temperature distribution is non-uniform at high Re and the temperature gradient is significantly higher compared to the low $\mathrm{Re}$ case. 


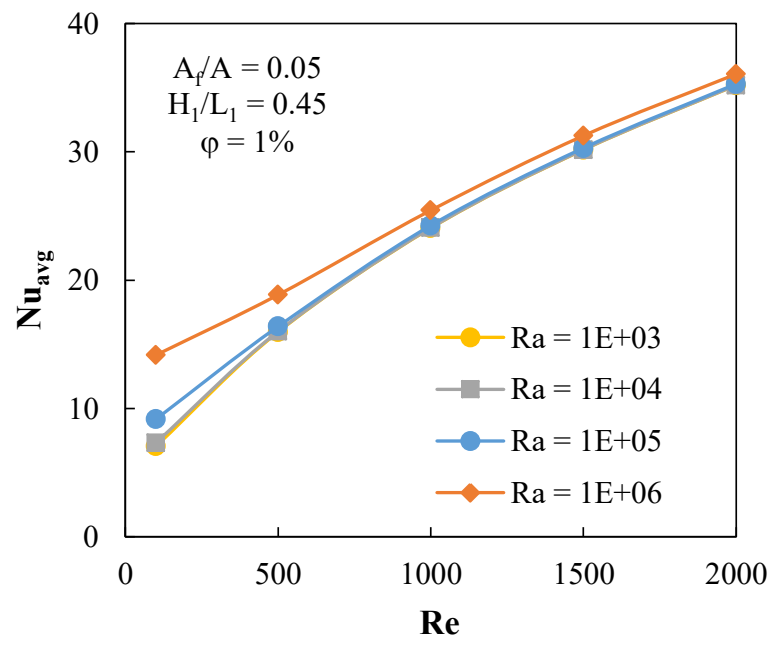

(a)

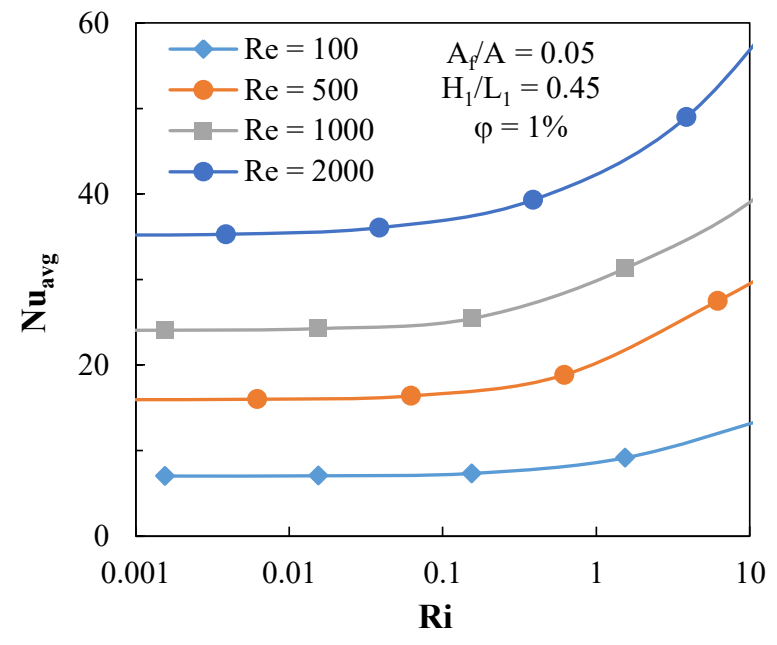

(b)

FIGURE 3. (a) Effect of Rayleigh number on the average Nusselt number. (b) Effect of Reynolds number on the average Nusselt number.

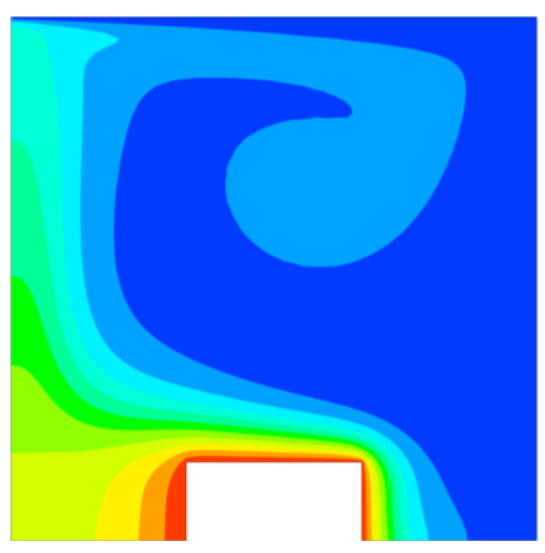

(a) $\operatorname{Re}=100$

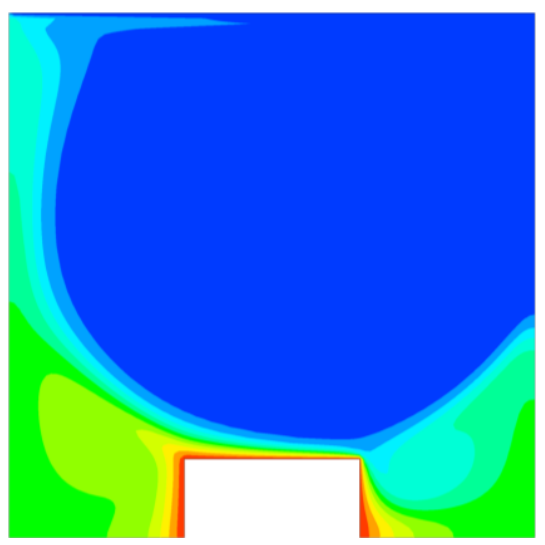

(c) $\operatorname{Re}=1000$

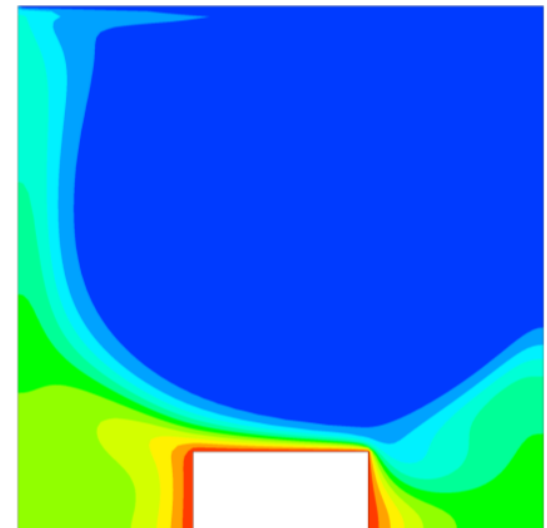

(b) $\operatorname{Re}=500$

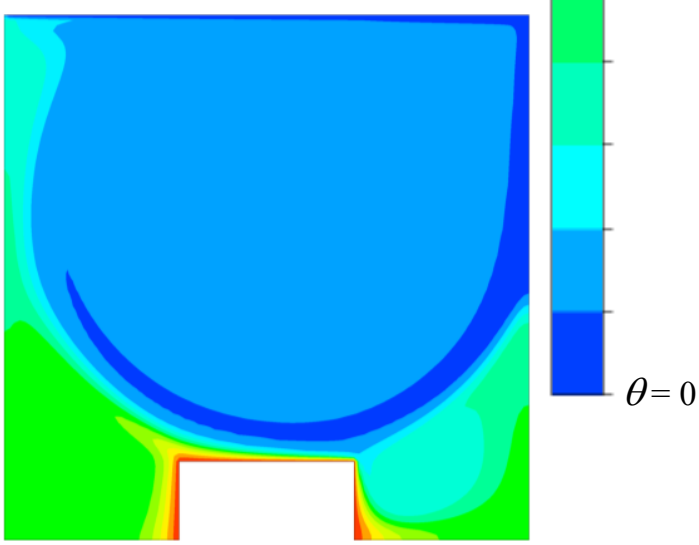

(d) $\operatorname{Re}=2000$

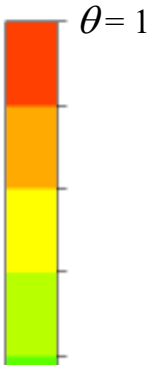

FIGURE 4. Isotherms for various Reynolds numbers under the same conditions as in Fig. 3. 
The influence of CuO-nanoparticles concentration on the average Nusselt number $\left(\mathrm{Nu}_{\text {avg }}\right)$ is shown in Figure 5. Three lines indicate three values of nanoparticles volume fractions $(\varphi)$, namely $1 \%, 2 \%$, and $4 \%$. It is obvious that the heat transfer condition is quite different due to the nanoparticles concentration. The higher volume fraction brings stronger heat transfer because it has more metal particles and higher thermal conductivity. Therefore, the $4 \%$ particle concentration of nanofluid has the best heat transfer performance in these three volume fraction cases. Although the nanoparticles concentrations are different, these three curves have the same trend. The lowest aspect ratio shows a higher $\mathrm{Nu}_{\text {avg }}$ than the highest aspect ratio. The maximum value of $\mathrm{Nu}_{\text {avg }}$ is observed for an intermediate aspect ratio, which is about 0.5 . This trend indicates that increasing the superficial area of fin does not provide a higher heat transfer from the fin. Thus, finding the optimum fin aspect ratio is essential.

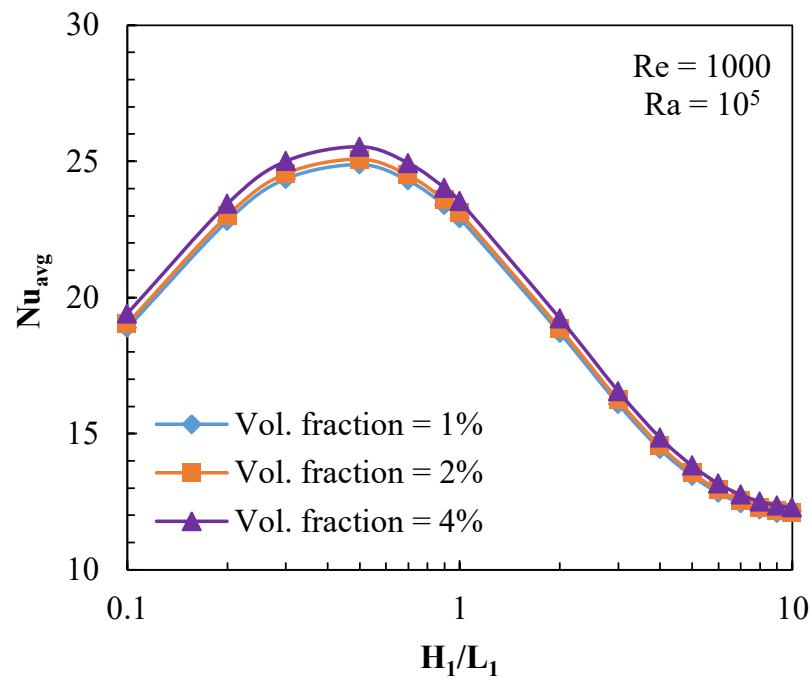

FIGURE 5. Effects of nanoparticles volume fraction on the average Nusselt number.

Table 4 shows the optimum fin aspect ratio $\left(\left(H_{1} / L_{1}\right)_{\mathrm{opt}}\right)$ as functions of Reynolds and Rayleigh numbers. It is observed that $\left(H_{1} / L_{1}\right)_{\text {opt }}$ changes with Reynolds number when the area ratio $A_{\mathrm{f}} / A=0.05$ for the two Rayleigh numbers, $10^{5}$ and $10^{7}$. The optimum fin aspect ratio is the one that maximizes the heat transfer between the fin and the surrounding $\mathrm{CuO}$-water nanofluid. The average Nusselt number, which is calculated at the optimum fin aspect ratio, is denoted as the maximum Nusselt number $\left(\mathrm{Nu}_{\max }\right)$ in Table 4 . For $\mathrm{Ra}=10^{5}$, it is noticed that the increase of Reynolds number does not significantly change the optimum fin aspect ratio. The values are within $1 \%$ of each other. When the Reynolds numbers are 100 and 500, the optimum ratio is 0.455 . While for $R e=1000$ and 2000, the optimum aspect ratio is equal to 0.45 . Although the optimum fin shape does not impact the Reynolds numbers when $\mathrm{Ra}=10^{5}$, the maximum average Nusselt number is increasing with the Reynolds number. As the function of the lid speed, the larger Nusselt number means the higher speed of the fluid flow in the enclosure, leading to larger inertial force inside the enclosure. The results of the present investigation indicate that higher fluid flow speed brings a larger magnitude of convection.

TABLE 4. Optimum fin aspect ratio and the maximum average Nusselt number as a function of Reynolds number for Ra $=10^{5}$ and $10^{7}$.

\begin{tabular}{ccccc}
\hline \multirow{2}{*}{$\operatorname{Re}$} & \multicolumn{2}{c}{$\mathbf{R a}=\mathbf{1 0}^{\mathbf{5}}$} & \multicolumn{2}{c}{$\mathbf{R a}=\mathbf{1 0}^{\mathbf{7}}$} \\
\cline { 2 - 5 } & $\left(\boldsymbol{H}_{\mathbf{1}} / \boldsymbol{L}_{\mathbf{1}}\right)_{\text {opt }}$ & $\mathbf{N u}_{\max }$ & $\left(\boldsymbol{H}_{\mathbf{1}} / \boldsymbol{L}_{\mathbf{1}}\right)_{\text {opt }}$ & $\mathbf{N u}_{\max }$ \\
\hline 100 & 0.445 & 9.159 & 0.535 & 19.744 \\
500 & 0.455 & 16.388 & 0.525 & 27.629 \\
1000 & 0.450 & 24.266 & 0.525 & 31.471 \\
2000 & 0.450 & 35.312 & 0.640 & 39.687 \\
\hline
\end{tabular}


For $\mathrm{Ra}=10^{7}$, the result is quite different. It is observed that the optimum fin aspect ratio becomes larger, which means the fin has to be taller and thinner in order to achieve the maximum convective heat transfer. When the Reynolds number is less than or equal to 1000 , the optimum fin aspect ratio is found to be in between 0.525 and 0.535 that is almost the identical trend of $\mathrm{Ra}=10^{5}$ cases. For $\mathrm{Re}=2000$, the optimum value increases to 0.64 and the height of the fin needs to be larger to achieve the maximum convective heat transfer. For the maximum Nusselt number under the optimum fin geometry, it can be observed that $\mathrm{Nu}_{\max }$ increases with the Reynolds number that is similar to the trend of $\mathrm{Ra}=10^{5}$ cases. Comparing these two cases of Rayleigh numbers, the optimum aspect ratio data have quite a different trend. The influence of Reynolds number on the optimum fin geometry is not significant when the Rayleigh number is $10^{5}$. However, the impact of Reynolds number on the optimum fin shape is remarkable for $\mathrm{Ra}=10^{7}$. When $\mathrm{Ra}=10^{5}$, the buoyancy force inside the enclosure is smaller and the forced convection dominates the heat flow inside the enclosure. When $\mathrm{Ra}=10^{7}$, the buoyancy force is more intense and the mixed convection becomes the dominant mode inside the enclosure. Thus, taller fins would be beneficial for higher Rayleigh numbers.

\section{CONCLUSIONS}

In this study, a two-dimensional numerical model has been developed for a square lid-driven enclosure with an intruded rectangular fin at the bottom to investigate mixed convection of $\mathrm{CuO}$-water nanofluid and to optimize fin geometry for maximizing the heat transfer. Various fin aspect ratios, Rayleigh numbers, Reynolds numbers, and Richardson numbers are investigated to understand the thermal behavior inside the enclosure. Based on the present investigation, it has been concluded that the fin geometry has a significant influence on the fluid flow and relative flow resistance. As a result, the heat transfer behaviors are strongly influenced by the fin aspect ratio. It has also been concluded that the increase of Reynolds number or the lid velocity can enhance the convection inside the enclosure. However, the optimum fin geometry remains independent of the Reynolds number. Conversely, the Rayleigh number has a strong influence on the fin geometry, particularly in the mixed convection regime. The addition of $\mathrm{CuO}$-nanoparticles in water shows a higher heat transfer from the fin and a higher concentration of $\mathrm{CuO}$ nanoparticles provides a better result due to the higher effective thermal conductivity.

\section{REFERENCES}

1. S. Ostrach, Adv. Heat Transfer 8, 161-227 (1972).

2. Y. Jaluria and S. K. Gupta, Int. J. Energ. Res. 7, 201-210 (1983).

3. D. Poulikakos and A. Bejan, J. Heat Transfer 105, 652-655 (1983).

4. E. Papanicolaou and Y. Jaluria, Numer. Heat Tr. A-Appl. 18, 427-461 (1990).

5. M. Peric, Numer. Heat Tr. A-Appl. 24, 213-219 (1993).

6. P. K. Das and S. Mahmud, J. Therm. Sci. 9, 135-140 (2000).

7. S. Mahmud, P. K. Das and N. Hyder, Int. Commun. Heat Mass 29, 993-1003 (2002).

8. S. Mahmud, P. K. Das, N. Hyder and A. K. M. S. Islam, Int. J. Therm. Sci. 41, 440-446 (2002).

9. $\quad$ P. K. Das and S. Mahmud, Int. J. Therm. Sci. 42, 397-406 (2003).

10. P. K. Das, S. Mahmud, S. H. Tasnim and A. K. M. S. Islam, Int. J. Numer. Methods Heat Fluid Flow 13, 1097-1122 (2003).

11. S. H. Tasnim, S. Mahmud and P. K. Das, Int. J. Numer. Methods Heat Fluid Flow 12, 855-869 (2002).

12. J. Rostami, Heat Mass Transfer 44, 1079-1087 (2008).

13. T. Basak, S. Roy, P. K. Sharma and I. Pop, Int. J. Therm. Sci. 48, 891-912 (2009).

14. M. Yousaf and S. Usman, Int. J. Heat Mass Transfer 90, 180-190 (2015).

15. J. A. Eastman, U. S. Choi, S. Li, L. J. Thompson and S. Lee, Mater. Res. Soc. Symp. P. 457, 3-11 (1997).

16. J. Buongiorno, J. Heat Transfer 128, 240-250 (2006).

17. J. Buongiorno, D. C. Venerus, N. Prabhat, T. Mckrell, J. Townsend, R. Christianson, Y. V. Tolmachev, P. Keblinski, L. W. Hu, J. L. Alvarado, I. C. Bang, S. W. Bishnoi, M. Bonetti, F. Botz, A. Cecere, Y. Chang, G. Chen, H. S. Chen, S. J. Chung, M. K. Chyu, S. K. Das, R. Di Paola, Y. L. Ding, F. Dubois, G. Dzido, J. Eapen, W. Escher, D. Funfschilling, Q. Galand, J. W. Gao, P. E. Gharagozloo, K. E. Goodson, J. G. Gutierrez, H. P. Hong, M. Horton, K. S. Hwang, C. S. Iorio, S. P. Jang, A. B. Jarzebski, Y. R. Jiang, L. W. 
Jin, S. Kabelac, A. Kamath, M. A. Kedzierski, L. G. Kieng, C. Kim, J. H. Kim, S. Kim, S. H. Lee, K. C. Leong, I. Manna, B. Michel, R. Ni, H. E. Patel, J. Philip, D. Poulikakos, C. Reynaud, R. Savino, P. K. Singh, P. X. Song, T. Sundararajan, E. Timofeeva, T. Tritcak, A. N. Turanov, S. Van Vaerenbergh, D. S. Wen, S. Witharana, C. Yang, W. H. Yeh, X. Z. Zhao and S. Q. Zhou, J. Appl. Phys. 106, 094312-1094312-14 (2009).

18. A. Bejan, Int. J. Heat Mass Transfer 40, 799-816 (1997).

19. A. Bejan and M. Almogbel, Int. J. Heat Mass Transfer 43, 2101-2115 (2000).

20. Y. M. Xuan and Q. Li, Int. J. Heat Fluid Flow 21, 58-64 (2000).

21. G. Lorenzini and L. A. O. Rocha, Int. J. Heat Mass Transfer 49, 4552-4557 (2006).

22. C. Biserni, L. A. O. Rocha, G. Stanescu and E. Lorenzini, Int. J. Heat Mass Transfer 50, 2132-2138 (2007).

23. M. R. Hajmohammadi, S. Poozesh and R. Hosseini, J. Therm. Sc. Tech. 7, 677-692 (2012).

24. G. Lorenzini, E. D. D. Estrada, E. D. Dos Santos, L. A. Isoldi and L. a. O. Rocha, Int. J. Heat Mass Transfer 83, 75-83 (2015).

25. R. Cong, X. Zhou, B. D. S. Machado and P. K. Das, AIP Conference Proceedings 1754, 050017 (2016).

26. J. C. Maxwell-Garnett, Philos. Trans. Roy. Soc. London Ser. A. 203, 385-420 (1904).

27. H. C. Brinkman, J. Chem. Phys. 20, 571-581 (1952).

28. P. K. Das, X. Li and Z. S. Liu, Appl. Energ. 87, 2785-2796 (2010).

29. P. K. Das, X. Li, Z. Xie and Z. S. Liu, Int. J. Energ. Res. 35, 1325-1339 (2011).

30. P. K. Das, A. Z. Weber, G. Bender, A. Manak, D. Bittinat, A. M. Herring and M. Ulsh, J. Power Sources 261, 401-411 (2014).

31. L. Xing, P. K. Das, X. G. Song, M. Mamlouk and K. Scott, Appl. Energ. 138, 242-257 (2015).

32. H. F. Oztop and E. Abu-Nada, Int. J. Heat Fluid Flow 29, 1326-1336 (2008). 